\title{
The Selection of Requirements at Special Shoes Design
}

\author{
Rimma R. FATKULLINA \\ Ph.D. (in Biological Sciences) \\ Associate professor \\ Materials and Technologies of Textile Industry Department \\ Faculty of Textile Industry Technology and Fashion \\ Kazan National Research Technological University \\ 68, Karl Marx Str., Kazan, 420015, Russia \\ rimma_fat@mail.ru \\ Lyudmila N. ABUTALIPOVA \\ Ph.D. (in Technical Sciences) \\ Professor \\ Materials and Technologies of Textile Industry Department head \\ Faculty of Textile Industry Technology and Fashion \\ Kazan National Research Technological University \\ 68, Karl Marx Str., Kazan, 420015, Russia \\ abutalipo@mail.ru \\ Azizbek Sh. SHERALIEV \\ Postgraduate \\ Materials and Technologies of Textile Industry Department \\ Faculty of Textile Industry Technology and Fashion \\ Kazan National Research Technological University \\ 68, Karl Marx Str., Kazan, 420015, Russia \\ aziikooo@mail.ru
}

\begin{abstract}
In some cases, it is necessary to use shoes elements based on polymers that can protect the foot from mechanical damage (punctures). The choice of rubbers for these purposes together with the intermediate polymer layer is due to the highly elastic and waterproof properties of the elastomers, as well as the anti-puncture properties of the aramid material, which ensure almost unchanged flexibility of the sole. The use as an alternative for these purposes of individual anti-puncture insoles is associated with certain material, technological difficulties and labor costs. So, it is necessary to develop a technological process creating a composite material providing protective properties for boots. Expert analysis is used when the requirements for design of special shoes are determined. The possibility of creating soles from composite material was tested. The composite material consists of three components: felt, polymeric textile and rubber. The adhesion is provided by the process of hot rubber vulcanization.
\end{abstract}

Keywords: expert analysis; material properties; footwear; felt; vulcanization.

\section{Introduction}

Safety footwear, along with workwear, is one of the necessary items of protective and work equipment that is used at enterprises. An efficient and safe professional activity is impossible 
without reliable special footwear. Today, there are various types of footwear designed to protect against harmful effects.

Work shoes are selected depending on the working conditions. The shoes must be waterproof if the worker has constant contact with moisture. The work shoes must be resistant to chemical influences if the field of activity is chemical production. The purpose of special industrial footwear is to create normal, comfortable working conditions, as well as to protect the foot, and sometimes the entire leg of the worker, from the factor of potential external influences.

The comfort of work shoes is determined by many factors: ease of donning and use; anthropological characteristics (shape, size, completeness); hygienic properties of footwear; ergonomic properties (lightness, flexibility); does not lose flexibility after moisturizing; ensures optimal heat transfer.

Leather is a strong and durable material that is one of the most widespread in production. Leather shoes will last a long time and provide good protection from mechanical damage. Rubber is used when it is necessary to provide protection against chemical, biological, environmental and electrical influences. Felt shoes are used at low and high temperatures. Felt has a low thermal conductivity, therefore it maintains the optimum temperature in the inner shoe space.

In Russia traditionally, wool is used to make clothes and shoes, since the climate is cold in winter. System design of cold weather protective clothing is described in works by Denner (1993) and Kasturiya, Subbulakshm, Gupta, and Raj (1999). The introduction of the new layers in the combat boot reduces, when compared to the usual combat boots, significantly the thermal strain and its weight. Therefore, the new boots maintained the security with greater comfort (Bradham, Beck, Barker, Montero, Deaton, 2011; Ormond, Barker, 2014; Thompson, Barker, Deaton, Montero, Bradham, Beck, Liston, 2010).

Indeed, systematic approach must be used for multilayer materials, and moreover the relationship of the layer elements must be taken into account. It is important to study protective and hygroscopic characteristics when we investigate the penetration of substance into the fabric. There is some research on experimental wet-heat treatments of woolen material (cloth). The parameters of shrinking in both directions after wet treatments, and changes structure are noted. The parameters of compression results, determination of hygroscopic and air permeability properties are analyzed (Khazanov, 2018).

In some cases, it is necessary to use shoe elements based on polymers that can protect the foot from mechanical damages (Liokumovich, 1980). The choice of rubbers $(R)$ for these purposes together with the wool $(F)$ and intermediate woven polymer layer $(P M-$ textile from basalt as model material) is due to the cold protective properties of felt, highly elastic and waterproof properties of the rubber, as well as the anti-puncture properties of the aramid material "Kevlar" ( $P K$ or model material PM), which ensure almost practically unchanged flexibility of the sole.

The use as an alternative for these purposes of individual anti-puncture insoles is associated with certain material, technological difficulties and labor costs. So, it is necessary to development a technological process for creating a composite material providing protective properties of boots.

Obviously, it is important to protect a person from mechanical puncture, low temperatures and moisture. To provide protective properties for design felted shoes, the following criteria were proposed: the properties of the material of the upper shoe $(F)$, the design, the properties of the materials of the bottom $(R)$, the properties of bottom materials as a package (in other words, a set of related materials, i.e., the system) materials $(F+P K+R)$ or $(F+P M+R)$, sole attachment method.

\section{Materials and Methods}


Wool fabric has a set of natural properties that give advantage to woolen and wool-containing products (Razumeev, 2002). If the felt fabric contains 100\% sheep wool, it has high cold weather resistance, because fibrous porous materials retain heat better then another textile.

The cross-sectional shape is most often flattened and irregular. Depending on the degree of homogeneity, and the average thickness of the fibers that form the fleece mass, the wool is classified into fine, semi-fine, semi-coarse and coarse. The wool fibers classified into down, transitional hair, awn, and dead hair. The length of semi-fine and semi-coarse wool is somewhat longer than that of fine wool. The coarse wool consists of a mixture of down, transitional hair, awn and dead hair. It is heterogeneous in length and linear density. The latter varies within a very wide range - from 1.2 to 3 tex. Wool crimpiness is characterized by the number of crimps per centimeter of fiber.

The thickness of the fibers varies widely depending on the type and has a great influence on the thickness, softness and elasticity of the yarn. The durability of the wool depends to a large extent on its structure. The relative breaking load and wear-and-tear resistance of fine wool is higher than that of coarse wool, because coarse fibers (awn and dead hair) have a core layer filled with air. The elongation of the fibers is determined by the elastic component of deformation, due to which the woolen fabrics do not wrinkle that much.

Woolen materials have found their application for the manufacture footwear (GOST 696-68 Army felted boots) due to the high strength properties and resistance to deformation. Woolen felted shoes for army performed on equipment, which has the traditional shape of boots. Felted shoes may have a difference, in the length of the bootleg. In addition, the design of boots may differ in the presence (absence) of reinforcing felt sole or sole made of rubber.

The seams method is used for felt soles fastening in the manufacture of felted shoes. For rubber sole attaching the chemical methods of pouring or hot vulcanization can be used. The advantage of chemical methods for attaching soles consists of the following points: 1) less mechanical work; 2) the absence of sewing needle holes; higher the strength of attaching, wear resistance, water resistance properties; resistance to low temperatures; 4) higher labor productivity; 5) the possibility technological automation.

The method of hot vulcanization is one of the most economical in shoe production. The thermal and power influences allow to receive adhesive interaction for felt and rubber. Elastomers (in the form of pieces and ribbons) for vulcanization of the shoe bottom should be well formed in the mold. They must have high fluidity, which can be achieved using stereoregular synthetic rubbers.

The thickness of the shoe bottom package system is reflected in the dimensional properties of shoes, affecting its mass. The choice of rubbers for these purposes together with the woven polymer layer and intermediate reinforcing material is due to the highly elastic and waterproof properties of the rubbers, as well as the anti-puncture properties of the intermediate reinforcing material and cold weather protective felt.

We used surveyed ten respondents (undergraduates in education "Technology of light industry") and ranking scores the criteria for design on special felted shoes (Table 1, Figure 1).

\section{Results and Discussion}

An analysis of the respondents' answers showed that the most important characteristics for felted shoes design were arranged in the following order: properties of the bottom materials as a package of materials $\rightarrow$ method of attaching the sole $\rightarrow$ protective properties of the materials of the top.

Table 1. Expert answers on the importance of the criteria for the design of felted shoes 
Fundamental and applied problems of materials creation and phases of technologies for textile industry

\begin{tabular}{|c|c|c|c|c|c|}
\hline $\begin{array}{c}\text { № } \\
\text { of } \\
\text { respondent }\end{array}$ & $\begin{array}{l}\text { Properties of the } \\
\text { bottom materials }\end{array}$ & $\begin{array}{l}\text { Sole attachment } \\
\text { method }\end{array}$ & $\begin{array}{c}\text { The properties } \\
\text { of the material } \\
\text { of the upper } \\
\text { shoe }\end{array}$ & $\begin{array}{c}\text { Design of } \\
\text { the } \\
\text { shoes }\end{array}$ & $\begin{array}{c}\text { Properties of bottom } \\
\text { materials as a } \\
\text { package }\end{array}$ \\
\hline 1 & 4 & 3 & 5 & 2 & 1 \\
\hline 2 & 3 & 4 & 2 & 1 & 5 \\
\hline 3 & 3 & 4 & 1 & 2 & 5 \\
\hline 4 & 1 & 4 & 3 & 2 & 5 \\
\hline 5 & 1 & 4 & 3 & 2 & 5 \\
\hline 6 & 1 & 3 & 4 & 2 & 5 \\
\hline 7 & 3 & 2 & 5 & 1 & 4 \\
\hline 8 & 1 & 3 & 4 & 2 & 5 \\
\hline 9 & 1 & 3 & 4 & 2 & 5 \\
\hline 10 & 3 & 4 & 2 & 1 & 5 \\
\hline Total & 21 & 34 & 33 & 17 & 45 \\
\hline
\end{tabular}

Indeed, the protective properties of each of the three components of sole, including low temperature protective - for felt, anti-puncture - for polymer intermediate material, deformation, water-proof for rubber, are important criteria for determining the protective properties of special shoes.

The comfort is important for the protective shoes (Fatkullina, Muhametchanov, Abutalipova, 2019), in particular, indicators of water capacity $\left(\mathrm{g} / \mathrm{m}^{2}\right)$, wetting angle (degrees), water penetrations (seconds), capillarity $(\mathrm{mm})$, porosity $(\%)$ (Table 2$)$. The characteristic of mass is included in the list of constructive technical requirements for personal protective equipment. So, it is important the dependence of the protective characteristics of the bottom (as a system of materials) on the thickness of the reinforcing and rubber layers of the sole (therefore the mass of the boots) (Table 3).

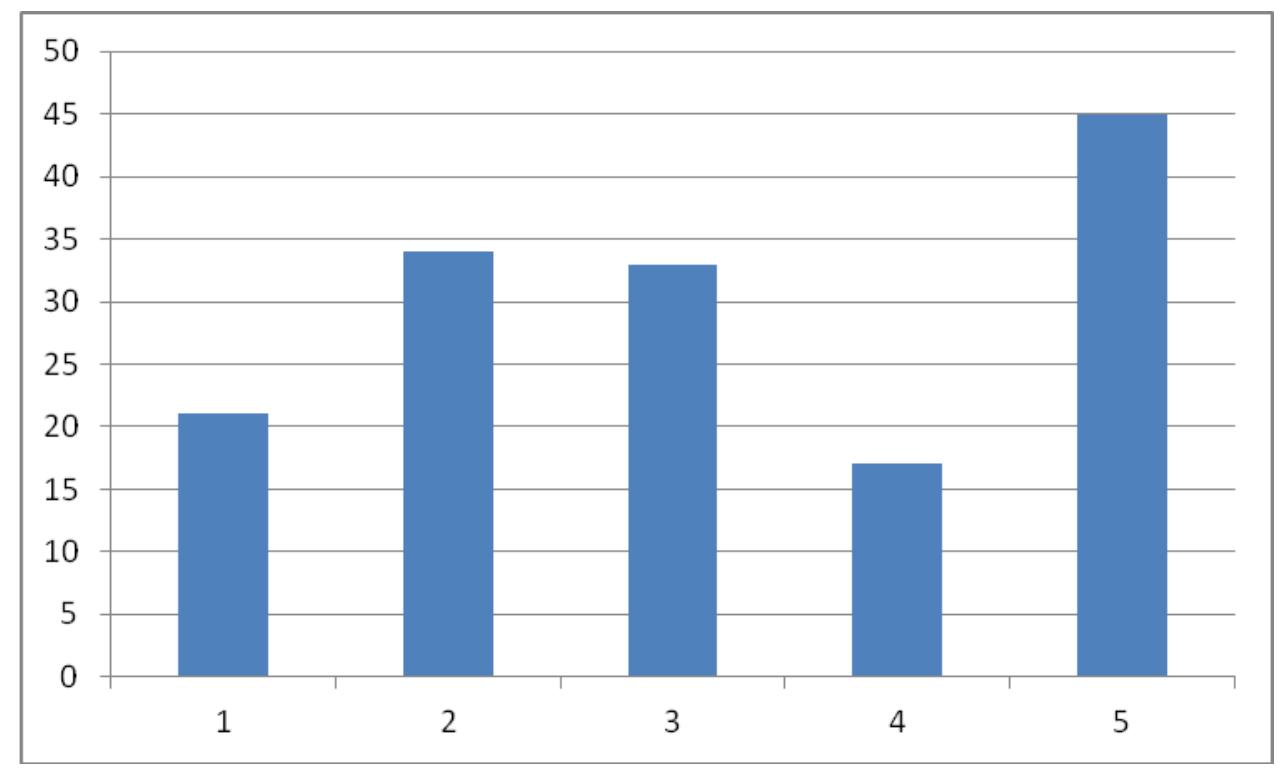

Figure 1. Weighting chart of special shoe design criteria: 1 - material properties of shoe soles; 2 - sole attachment method; 3 - properties of the upper materials of shoes; 4 - shoe design; 5 properties of bottom materials as a package of materials 
The main structural and dimensional characteristics of the materials used on design of felted shoes are: the fibrous and polymer composition, surface density $\left(\mathrm{g} / \mathrm{m}^{2}\right)$ and thickness $(\mathrm{mm})$. The deformation properties (flexibility and elasticity) depend on polymer composition, as well as the dimensional properties of the materials.

Table 2. Hydroscopic characteristics of the materials used in the design of felted shoes (+ research is necessary with the selection or optimization of characteristics; - - research is not required)

\begin{tabular}{|c|c|c|c|c|c|}
\hline Characteristics & $\begin{array}{l}\text { Water capacity } \\
\left(\mathrm{g} / \mathrm{m}^{2}\right)\end{array}$ & $\begin{array}{l}\text { Wetting angle, } \\
\text { degrees }\end{array}$ & $\begin{array}{l}\text { Water penetrations } \\
(\mathrm{sec})\end{array}$ & Capillarity (mm) & $\begin{array}{l}\text { Porosity } \\
(\%)\end{array}$ \\
\hline $\mathrm{F}$ & + & + & + & + & + \\
\hline $\mathrm{R}$ & - & - & - & - & + \\
\hline PK or PM & + & - & + & + & - \\
\hline
\end{tabular}

In order to optimize the strength characteristics of sole made of composite material, one should study the process of penetration of the vulcanized rubber into the fibrous of the felt through the mesh structure of the reinforcing aramid material; to investigate the dependence of strength and protective characteristics of shoes on the thickness of the reinforcing and rubber layer (and, consequently, the mass of product) (Table 3 ).

Table 3. Deformation, protective (strength), dimensional properties of shoes bottom as a package

\begin{tabular}{|c|c|c|c|c|c|c|}
\hline $\begin{array}{l}\text { Layers of } \\
\text { composition }\end{array}$ & $\begin{array}{l}\text { Elasticity, } \\
\qquad s m\end{array}$ & $\begin{array}{l}\text { Flexibility, } \\
{ }^{\circ}(\text { degrees })\end{array}$ & $\begin{array}{l}\text { Hardness } \\
\text { coefficient }\end{array}$ & $\begin{array}{l}\text { Anti-puncture properties, } \\
\qquad N\end{array}$ & $\begin{array}{c}\text { Thickness, } \\
\text { mm }\end{array}$ & $\begin{array}{c}\text { Mass, } \\
\quad g\end{array}$ \\
\hline $\mathrm{F}+\mathrm{PK}+\mathrm{R}$ & + & + & + & + & + & + \\
\hline $\mathrm{F}+\mathrm{PM}+\mathrm{R}$ & + & + & + & - & - & - \\
\hline $\mathrm{F}+\mathrm{R}$ & + & + & + & + & + & + \\
\hline
\end{tabular}

We can use multilayer sole in which inner layer made of non woven wool for absorbing the sweat and to store the heat released by the foot then polymeric layer for sharp object protection and then outermost waterproof rubber layer. Basalt material was manually cut by pulling threads to improve layer contact then it was used as a model fabric, which can be replaced with Kevlar material (made from aramid fibers). The layers of the composite material are glued by hot rubber vulcanization. The adhesion of the layers provides strength properties of composite material.

\section{Conclusion}

Thus, expert survey provided the following answers received the greatest weight from the exploitation point of view: properties of the bottom materials of the shoe (sole) as a package of materials (composite material) $\rightarrow$ method of attaching the sole $\rightarrow$ protective properties of the upper materials. There are important criteria for the improvement of felted army boots: resistance to mechanical stress, moisture; deformation properties. Besides them the mass is important for boots exploitation.

We propose the manufacturing process for soles with protective anti-puncture properties. The 
manufacturing vulcanization process allows fix anti-puncture material between the felt layer and the rubber sole layer. So doing composition material may be use for design of few models shoes.

Recommendation. It is supposed to reduce the thickness of the rubber layer, and therefore the mass of army boots, which has the specified strength characteristics for the emergency services.

\section{References}

Bradham, A.E., Beck, K.R., Barker, R.L., Montero, G.A., Deaton, A.S. (2011). Analytical techniques for measuring toxic industrial chemicals in CBRN boot materials. AATCC Review, 11(6).

Denner, J. (1993). A primer on clothing systems for cold-weather field work. Bow, New Hampshire: U.S. Geological Survey, pp.89-415.

Fatkullina, R.R., Muhametchanov, N.I., Abutalipova, L.N. (2019). Topography of protection and criteria of comfortable special footwear. Proceedings of International scientific and technical symposum "Modern engineering problems in consumer goods production", International Kosygin Forum «Modern problems of engineering sciences» (2019, 29-30 of October), 203-206.

Kasturiya, N., Subbulakshm, M., Gupta, S., Raj, H. (1999). System Design of Cold Weather Protective Clothing. Defence Science, 49(5), 457-464.

Khazanov, G.I. (2018). The study of changes in the physical, physico-mechanical and hygroscopic properties of technical woolen cloth during the washing process. Design, Technologies and Innovations in the Textile and Light Industry (Innovations-2018): proceedings of International scientific and technical conference, 87-89.

Liokumovich, V.Kh. (1980). Structural analysis of shoe quality. Moscow: Light industry.

Ormond, R.B., Barker, R.L. (2014). Chemical, biological, radiological and nuclear (CBRN) protective clothing. In: Protective Clothing: Managing Thermal Stress, 112-145. Elsevier Inc.

Razumeev, K.E. (2002). Unique properties of wool. Textile industry, 11, 8-10.

Thompson, D.B., Barker, R.L., Deaton, A.S., Montero, G.A., Bradham, A.E., Beck, K.R., Liston, G.C. (2010). Chemical resistant leather materials for CBRN boots. In: American Association of Textile Chemists and Colorists International Conference 2010, pp. 407-413. 